[CONTRIbUtion from the Wolcott Gibes Memorial Laboratory of HaRvard UNIVERSITY.]

\title{
THE SOLUBILITY OF SODIUM SULFATE AS A MEANS OF DETERMINING TEMPERATURES.
}

BY THEODORE W. RICHARDS AND VICTOR YNGVE.

Received November 18, 1917.

The accurate fixing of temperatures is becoming more and more important in view of the increasing exactness of physico-chemical measurements. Among the definite points employed, those involving a single component, such as the melting point of ice and the boiling point of water under atmospheric pressure, are most common. ${ }^{1}$ Quadruple points, or more strictly speaking, bicomponent transitions under definite pressure, such as the transition temperatures of hydrated salts, also serve excellently. ${ }^{2}$ Other methods employing two components, such as the freezing points of dilute aqueous solutions, ${ }^{3}$ or the floating equilibrium of a known float in a solution whose density is changed by adding an easily determined solute until an exact equilibrium is obtained at the temperature in question, ${ }^{4}$ or a thermochemical method ${ }^{5}$ may be used in emergencies.

Of course, any definite property of material possessing a large temperature coefficient could be used for this purpose. If the solubility of salts has not been used before (we can find no reference to its use), the reason has been, perhaps, a doubt concerning the certainty of obtaining exact saturation, and the lack of adequate data. Indeed, nearly, if not quite all, of the published results of this kind are not of the order of accuracy required.

In order that a salt may serve as a means of fixing temperatures with precision through the determination of its solubility at any point in question, it must possess a large temperature coefficient of solubility; its solutions must be easily saturated, but not easily supersaturated; it must be readily determinable quantitatively, and must not be difficult to obtain in a high degree of purity. Many substances possess three of these requirements. With regard to definiteness of saturation, we were guided by van't Hoff's experience that univalent metals are better than bivalent. ${ }^{6}$

${ }^{2}$ For a convenient list of recently found values of a number of such points, see Bureau of Standards, Bull. 35, Ed. 2 (I915).

2 This method was first proposed in 1866 , but the proposal was forgotten and buried. Apparently it was first applied practically in 1898 . For references see Richards and Fiske, This Journal, 36, 486 ( 1914 ); also p. 89 of this number.

${ }^{3}$ Richards and Jackson, Proc. Am. Acad. Arts Sci, 4I, 45 I (rgo6).

4 Richards and Shipley, THIS JournaL, 36, 1-ro (1914).

${ }^{5}$ Richards and Thorvaldson, ThIs Journal, 37, 8I (I9I5).

'One of the authors remembers having heard orally from van't Hoff that the latter came to this conclusion in the course of his work on the Stassfurt salts; a published reference to this conclusion has not yet been found. 
Sodium sulfate seemed to possess the necessary qualities in as happy conjunction as any, and it was accordingly chosen for detailed study.

\section{Historical.}

The solubility of sodium sulfate has been determined by many investigators. The determinations which are chosen as best by LandoltBörnstein-Roth between the temperatures of $15^{\circ}$ and $25^{\circ}$ are those of Loewel ${ }^{1}$ and the Earl of Berkeley. ${ }^{2}$ Loewel's thermometer was not described in detail, but Lord Berkeley's had been standardized at Kew, and was doubtless better, although rendered somewhat doubtful by a slight uncertainty in the ice point. Neither of these series of measurements which are given below, is precise enough for the object in hand.

TABLE I.-EARIIER DATA CONCERNING the SOLUBILITY of $\mathrm{Na}_{2} \mathrm{SO}_{4} \cdot \mathrm{IOH}_{2} \mathrm{O}$ IN WATER.

\begin{tabular}{ccc} 
& \multicolumn{2}{c}{$\mathrm{Na}_{2} \mathrm{SO}_{4}$ in $100 \mathrm{~g} . \mathrm{H}_{2} \mathrm{O}}$. \\
Temp. & Loewel. & Berkeley. \\
15.00 & 13.20 & $\ldots$ \\
15.65 & $\ldots$ & 14.07 \\
18.00 & 16.80 & $\ldots$ \\
20.00 & 19.40 & $\ldots$ \\
24.90 & $\ldots$ & 27.67 \\
25.00 & 28.00 & $\ldots$
\end{tabular}

\section{Purification of Materials.}

In most of our determinations the purest water was used, prepared by redistilling ordinary distilled water, first from alkaline permanganate, and then from a trace of sulfuric acid with a block tin condenser. Ordinary laboratory steam-distilled water was used in a few trials, and gave exactly the same result for the solubility of sodium sulfate as did the purest water.

"Chemically pure" sodium sulfate was four times recrystallized in porcelain and drained in the centrifuge, a portion of the thrice recrystallized product being reserved for comparison. No difference could be found in the solubility of the two specimens; hence further crystallization was deemed unnecessary. Evidence of purity is also afforded by the fact that such material almost always gives a constant transition temperature, even after many further crystallizations. ${ }^{3}$ Our experience thus shows that both water and sodium sulfate are easily obtained in a state pure enough for the purpose in hand.

\section{The Experimental Procedure for Determining Solubility.}

The method of procedure was chosen so that it might combine simplicity and ease of manipulation with the requisite degree of accuracy. Coarsely granular crystals, about $\mathrm{I}$ to $3 \mathrm{~mm}$. in diameter, were placed

${ }^{1}$ Loewel, Ann. chim. phys., [3] 49, 50 (1857).

2 Berkeley, Phil. Trans., (A) 203, 209 (1904).

${ }^{3}$ Richards and Wells, Proc. Am. Acad. Arts Sci., 38, 435 (1902). 
in a wide test tube $3 \mathrm{~cm}$. in diameter and $15 \mathrm{~cm}$. long. Water was added to fill the tube to within $3 \mathrm{~cm}$. from the top and a thoroughly cleaned rubber stopper was fitted to the opening. Thin wide rubber tubing was drawn over the rubber stopper and the lip of the test tube in order to keep the lip of the test tube dry. Finally the stopper was wired in place in order to prevent the possibility of its accidental dislodgement. The test tube was then secured by rubber bands to a strip of brass soldered at right angles to a revolving axle, and rotated in a thermostat which was maintained constant in temperature within $0.001^{\circ}$. This method attains saturation much more quickly than that which depends upon stirring the solution above resting crystals. The equilibrium is, of course, established only on the surface between the two phases, and the speed of its attainment is accelerated by promoting diffusion and convection immediately on the surface. The rotation was at the rate of forty revolutions per minute, a speed which gave ample stirring and yet was not violent enough to produce fine particles which would give the solubility an uncertain value. It is well known that the solution tension of a fine powder presenting sharply curved surfaces has a higher value than the flat surface of the same substance. ${ }^{1}$

In due time the rotation was stopped. The upper part of the test tube was brought to the surface of the bath by raising the whole rotating apparatus, and the wire and protecting rubber tube were carefully removed. The stopper was then withdrawn and two successive portions of the solution immediately removed by means of a filtering pipet, which consisted at first of an ordinary pipet with an attached rubber tube connecting successively extra tips loosely plugged with pledgets of cotton wool. ${ }^{2}$ Before attaching the filtering device the pipet was provided with a large rubber stopper which closed the test tube when the pipet was lowered into it. A notch in this stopper providing inlet for air to displace the solution with drawn from the test tube. The pipet was kept at a proper temperature by enclosing it is a dry receptacle or sheath immersed in the thermostat. This method of removing the solution would, of course, need to be modified for use with higher temperatures, when evaporation would otherwise vitiate the results; but no trouble from this source seems to have arisen in our experiments, judging from the usual identity of analyses $\mathrm{A}$ and $\mathrm{B}$, taken out one after the other from the same receptacle.

After withdrawing each portion of the solution from the test tube,

${ }^{1}$ P. Curie, Bull. soc. chim., 8, I45 (1885); see also G. A. Hulett, Z. physik. Chem., 37,385 (1901).

${ }_{2}^{2}$ Richards and Fraprie, Proc. Am. Acad. Arts Sci., 36, 5 ro (rgor). The pledgets of cotton were very small, hence the effect of adsorption must have been negligible. Comparison of results involving different bulks of solution, and those with the different forms of pipet, confirms this conclusion. 
the filtering attachment was quickly removed and (in the earlier determinations) the solution was run into a weighing bottle, which was immediately stoppered and weighed. Later it was found to be more convenient to provide the pipet with a stopcock and to weigh the solution in the pipet itself, from which the liquid could be run directly into the platinum vessel used for evaporation. Samples withdrawn by each of these methods gave the same value (within the limit of error) for the solubility in the series (that at $25^{\circ}$ ) where both were used. Expts. I to 6, inclusive, were withdrawn by the first method; Expt. 7 by the second.

The solutions were evaporated to complete dryness in platinum basins on a steam bath duly protected from contamination by large watch glasses secured about $6 \mathrm{~cm}$. above them. The residue was cautiously heated over a Bunsen flame, at first turned very low but gradually increasing in an hour to full intensity, while the platinum basins were kept closely covered by means of small, thin watch glasses. Such gradual heating causes but very little, it any, decrepitation. Only once was a determination lost from this cause - in this case it had been heated too quickly. If a few minute particles of the sulfate are found clinging to the watch glass they may be easily returned to the dish. The total residue was then fused at a barely adequate red heat, just above $884^{\circ}$, to constant weight, which was usually attained at once.

The weighings were made after complete cooling, by substitution against a suitable counterpoise. In the case of the solutions the counterpoise was either a weighing bottle or a weight pipet, respectively, similar to the ones used with the solution; in the case of the platinum dishes the counterpoise consisted of equal weights of other platinum vessels. The weights were standardized carefully by the usual method. ${ }^{1}$ All the weighings were corrected to the vacuum standard, assuming the density of sodium sulfate to be $2.698^{\circ}, 2$ and driving the densities of the solution by interpolation from the data given by Lord Berkeley. ${ }^{3}$

\section{The Definiteness of the Equilibrium.}

Theoretically, such an equilibrium as that between sodium sulfate dekahydrate and its aqueous solution must be perfectly definite, but in practice some systems approach equilibrium so slowly that their use would be precluded. Unless a definite equilibrium is promptly attained, the whole attempt would be in vain. Therefore, the time of digestion was varied over wide limits, and it was found that equilibrium was very quickly established, as is easily seen in the tables of results given here-

1 T. W. Richards, This Journal, 22, I44 (I900).

2 Richards and Hoover, Ibid., 37, II I (I9I5).

${ }^{3}$ Earl of Berkeley, Phil. Trans., (A) 203, 209 (1904). For solutions saturated at $15.65^{\circ}, 20.35^{\circ}, 24.90^{\circ}$, the densities were found by him to be I.II5, I.I55 and I.207, respectively. 
with. Even at $15^{\circ}$, where the attainment of equilibrium is naturally slower than that at higher temperatures, one-half hour's agitation in the apparatus (No. 18 ) served to give almost precisely the same degree of saturation as two hours (No. 16), and in other trials even five or six hours produced no further effect. Moreover, the equilibrium was approached from both sides, in order to be sure that no accidental errors existed. Measurements in which the system was brought from a lower temperature to that of the thermostat (Nos. I, 3, 5, 8, 9, I0, II, I3, I4, I6, 18) agreed with corresponding measurements in which the system was brought from a higher point to this same temperature (Nos. 2, 6, 9, 7, I2, $15,17)$. No. I9 was made after all the others, in order to be sure that the early values near $25^{\circ}$ could be repeated. Evidently, then, this system is excellently adapted to serve the purpose for which it was chosen; it combines all the necessary qualities in adequate fashion.

Tests were made to see if the glass test tubes were appreciably soluble in solutions of sodium sulfate. Two test tubes containing sodium sulfate solution and an excess of crystals were rotated at a temperature of $24^{\circ}$ for a period of two hours. One was a test tube which had been used in several solubility experiments, and the other a new tube, which had been thoroughly cleaned in a manner sinilar to that used in the actual experiments. The tubes were weighed against a similar counterpoise before and after the rotation. Test tube I gained $0.05 \mathrm{mg}$. and test tube II showed no appreciable change in weight. Clearly the solubility of the glass was too slight (at these temperatures and in these comparatively short times) to affect the result.

\section{Ascertaining the Temperatures.}

An accurate Beckmann thermometer (more convenient than the standard thermometers for the measurement of small fluctuations) indicated the temperature of the thermostat, and this thermometer was then compared with the standard Baudin thermometers Nos. 1527 and I520. The latter were read (by means of an accurate Geneva cathetometer) many times from both sides in order to avoid any errors which might be due to irregularities in the glass. The mean of all readings was taken as the uncorrected reading for that temperature. The ice points were determined in the usual way and all the precautions mentioned by Guillaume ${ }^{1}$ were observed. A typical example of the full data of a single determination is given below. It will be observed that special heed was given to the effect of pressure on the thermometers.

This value $\left(14.733^{\circ}\right)$ is the hydrogen scale reading corresponding to $0.290^{\circ}$ on the Beckmann under $740 \mathrm{~mm}$. pressure. Hence with the corrected barometer at 746 and Beckmann at 0.290 the reading

'Guillaume, "Traite de la Thermometrie," I889. 
would have been $14.732^{\circ}$, since the effect of $10 \mathrm{~mm}$. pressure on the Beckmann bulb was $0.002^{\circ}$. $14.732^{\circ}$ was therefore taken as the true temperature at the time of solubility Expt. No. I8.

\section{TABLE II.}

Full Data of Determination I8.

Barometer $746 \mathrm{~mm}$., Beckmann $0.290^{\circ}$.

Analysis A.

Wt. of solution $4 \mathrm{I} .0384$

Vacuum correction (density of solution r.107).... +o.0385

Corrected wt. of solution.

Wt. of $\mathrm{Na}_{2} \mathrm{SO}_{4}$

Vacuum correction (density 2.698 )

Corrected wt. of $\mathrm{Na}_{2} \mathrm{SO}_{4} \ldots \ldots \ldots \ldots \ldots \ldots \ldots$

Wt. of $\mathrm{H}_{2} \mathrm{O}$

G. $\mathrm{Na}_{2} \mathrm{SO}_{4}$ per $100 \mathrm{H}_{2} \mathrm{O}$

$$
\begin{array}{r}
41.0769 \\
4.7002 \\
+0.0015 \\
\hline 4.7017 \\
36.3752 \\
12.926
\end{array}
$$

Determination of Temperature.

Barometer 740 mm., Beckmann $0.290^{\circ}$.

Baudin thermometer No . . . . . . . . . . . . . . . . 15.276

Observed reading. ...................... 14.968

Cors. for calibration. . . . . . . . . . . . . . . . . . . -0.043

Corr. for exterior pressure................. +o.002

Corr. for interior pressure................ +0.033

Corr. for fundamental interval.............. +o.001

Corr. for similarly corrected ice point.......... $\rightarrow .160$

15.200

I5.00I

$\multimap 0.009$

$+0.002$

to.023

to.010

$\longrightarrow .222$

14.805

Corr. to hydrogen scale.

$$
14.801
$$

$-0.070$

Final values 1

$$
-0.070
$$

$14 \cdot 73 \mathrm{r}$

14.735
Analysis B.

.8057

21.8261

2.4973

2.498

19.3280

2.925

Mean value.

$14.733^{\circ}$

The following table (Table III) contains the results, the temperature and solubilities being ascertained in precisely the manner indicated in Table II. All of the results obtained are given in the following table, excepting determination 4 , in which the thermostat was so inconstant as to make the result meaningless, and Analysis B of determination 2, which was invalidated by known loss from explosive decrepitation. In Nos. 5, 7, I2 and I5 only one analysis was made. The last column gives the individual values corrected to the exact temperatures designated as pertaining to the average in each case. The correction to be applied to the mean values given in the next to the last column is easily found in each case from the solubility curve. For each $0.001^{\circ}$ it amounts at $25^{\circ}$ to $2.0 \mathrm{mg}$.; at $22.5^{\circ}, \mathrm{I} .7 \mathrm{mg}$.; at $20^{\circ}, \mathrm{I.4} \mathrm{mg}$; 站 $17.5^{\circ}, \mathrm{I} .2 \mathrm{mg}$.; and at $15^{\circ}$, r.o mg.

1 The difference between the corrected Baudin thermometers was rarely as great as in this case. Usually they agreed with one another within $0.002^{\circ}$. 
TABLE III.

Determination at $25^{\circ}$.

Concentration of solution, g. salt per $100 \mathrm{~g}$. water.

\begin{tabular}{|c|c|c|c|c|c|c|}
\hline No. & Time. & $\begin{array}{l}\text { Temperature } \\
\text { (Hydrogen } \\
\text { scale.) }\end{array}$ & Analysis A. & $\begin{array}{c}\text { Analysis } B . \\
\text { G. }\end{array}$ & $\begin{array}{c}\text { Mean. } \\
\text { G. }\end{array}$ & $\begin{array}{c}\text { Corrected } \\
\text { mean. } \\
\mathrm{G} .\end{array}$ \\
\hline & $3 \mathrm{hrs}$ & $24.845^{\circ}$ & 27.468 & 27.468 & 27.468 & 27.468 \\
\hline 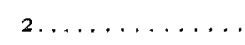 & $6 \mathrm{hr}$ & 24.8 & $27 \cdot 465$ & . & 24.465 & 27.465 \\
\hline $3 \ldots \ldots \ldots \ldots$ & 3 hrs. & 24.8 & 27.475 & 27.474 & 27.475 & 27.467 \\
\hline & & 24 . & 27.475 & . & 27.475 & $27.47 \mathrm{I}$ \\
\hline & & $24.847^{\circ}$ & 27.470 & 27.473 & $27.47^{2}$ & 27.468 \\
\hline$\ldots$ & I hr. & $24.843^{\circ}$ & 27.463 & 27.460 & 27.462 & 27.466 \\
\hline
\end{tabular}

Solubility at $24.845^{\circ}$ per $100 \mathrm{~g}$. water: Mean, 27.468

$\begin{array}{llllccc}7 \ldots \ldots \ldots \ldots \ldots & 3 \mathrm{hrs} . & 22.265^{\circ} & 22.597 & \ldots & 22.597 & 22.597 \\ 8 \ldots \ldots \ldots \ldots \ldots & 5 \text { hrs. } & 22.265^{\circ} & 22.607 & 22.600 & 22.604 & 22.604 \\ 9 \ldots \ldots \ldots \ldots \ldots & \text { r hr. } & 22.265^{\circ} & 22.602 & 22.602 & 22.602 & 22.602\end{array}$

Solubility at $22.265^{\circ}$ per I00 g. water: Mean, 22.601

$\begin{array}{lllllll}\text { Io } \ldots \ldots \ldots \ldots \ldots & 2 \mathrm{hrs}, & 19.857^{\circ} & 18.859 & 18.858 & 18.859 & 18.863 \\ 1 \mathrm{I} \ldots \ldots \ldots \ldots & 2 \mathrm{hrs} . & 19.861^{\circ} & 18.873 & 18.872 & 18.873 & 18.872 \\ 12 \ldots \ldots \ldots \ldots \ldots & 3 \mathrm{hrs} . & 19.860^{\circ} & 18.863 & \ldots & 18.863 & 18.863\end{array}$

Solubility at $19.860^{\circ}$ per $100 \mathrm{~g}$. water: Mean, 18.866

$\begin{array}{ccccccc}13 \ldots \ldots \ldots \ldots \ldots & 2 \mathrm{hrs} . & 17.472^{\circ} & 15.805 & 15.805 & 15.805 & 15.805 \\ 14 \ldots \ldots \ldots \ldots & 3 \mathrm{hrs} . & 17.470^{\circ} & 15.807 & 15.804 & 15.806 & 15.808 \\ 15 \ldots \ldots \ldots \ldots & 2 \mathrm{hrs} . & 17.472^{\circ} & 15.807 & \ldots & 15.807 & 15.807\end{array}$

Solubility at 17.472 per $100 \mathrm{~g}$. water: Mean, 15.807

$\begin{array}{lllllll}16 \ldots \ldots \ldots \ldots \ldots & \text { 2 hrs. } & 14.732^{\circ} & 12.926 & 12.924 & 12.925 & 12.924 \\ 17 \ldots \ldots \ldots \ldots \ldots & \text { I hr. } & 14.731^{\circ} & 12.925 & 12.924 & 12.925 & 12.925 \\ 18 \ldots \ldots \ldots \ldots \ldots & 1 / 2 \mathrm{hr} . & 14.732^{\circ} & 12.926 & 12.925 & 12.926 & 12.925\end{array}$

Solubility at $14.731^{\circ}$ per $100 \mathrm{~g}$. water: Mean, 12.925

Thus five results for the solubility of sodium sulfate covering a range of ten degrees are provided, and the problem remains to interpolate other values between them. This may, of course, be done approximately by means of a graph; but since this graph would have to be drawn on a very large scale in order to attain a degree of accuracy, equalling that of the analytical work, it seemed worth while to derive an equation fitting the points as nearly as possible. The known values for the solubilities at $14.731^{\circ}, 19.860^{\circ}$ and $20.845^{\circ}$ were substituted in the equation

$$
\log \mathrm{S}=a+b t+c t^{2} .
$$

The three equations were solved simultaneously for $a, b$ and $c$. The result follows:

$$
\log S=0.6600577+0.0296154 t+0.000069619 \mathrm{r} t^{2} .
$$

The solubilities for $17.472^{\circ}$ and $22.265^{\circ}$ were then computed and found to agree closely but not exactly with those found at these temperatures. The results are given in Table IV:

${ }_{1}^{1}$ Nordenskiold, Ann. Phys., [2] 136, 309 (1869). 


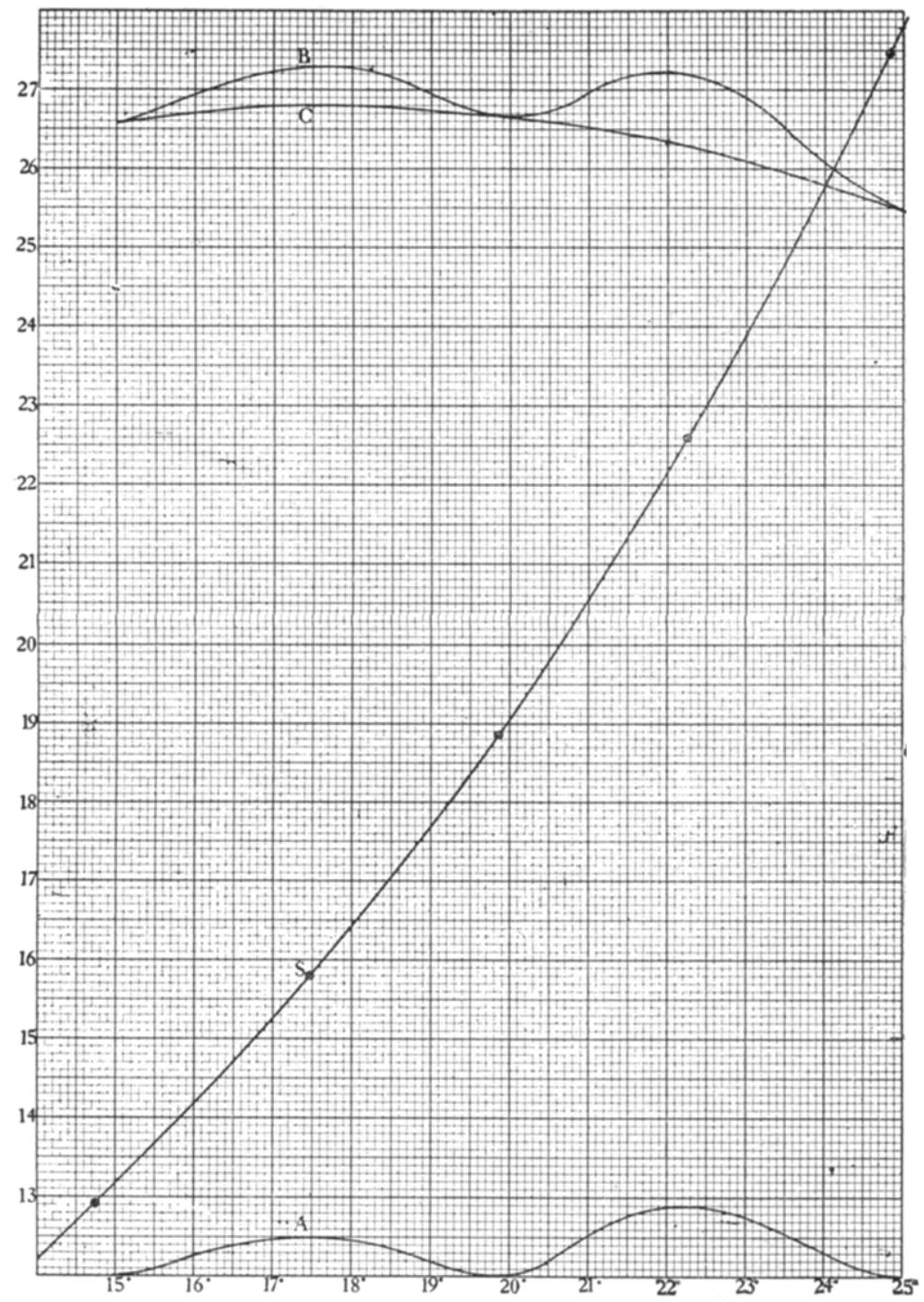

Solubility of Sodium Sulfate.

The diagonal curve (S) represents the solubility of sodium sulfate, grams of salt per 100 grams of water being plotted in the direction of ordinates, and degrees centigrade as abscissas. (The difference between the two standards of temperature is less than the thickness of this line as drawn.)

Curve A, the undulating deviation curve at the bottom, indicates (reading upward) the correction to be added to the value from Equation II at any given temperature in order to obtain the solubilities in terms of the Baudin hydrogen scale. Curve B, the undulating deviation curve at the top, similarly indicates (reading downward from the top of the diagram) the correction which must be subtracted from the value from Equation II in order to obtain the solubility in terms of the platinum scale of temperature (as indicated by Dr. H. N. Davis's platinum thermometers). Curve C, just below Curve B (also reading downward), records the number of milligrams to be subtracted from each solubility as recorded in Table V, in order to reduce the data to the platinum scale. In the case of the three deviation curves, the scale is magnified Ioo times; each small square in the direction of ordinates indicates $1 \mathrm{mg}$. 


\begin{tabular}{cccc} 
& \multicolumn{3}{c}{ TABLE IV. } \\
Temperature. & $\begin{array}{c}\text { Solubility. } \\
\text { Found. }\end{array}$ & $\begin{array}{c}\text { Solubility calc. } \\
\text { Equation IY. }\end{array}$ & \multicolumn{1}{c}{. } \\
$14.73 \mathrm{I}$ & $\mathrm{I} 2.925$ & 12.925 & 0.000 \\
17.472 & 15.807 & 15.802 & -0.005 \\
19.860 & 18.866 & 18.866 & 0.000 \\
22.265 & 22.601 & 22.592 & -0.009 \\
24.845 & 27.468 & 27.468 & 0.000
\end{tabular}

Evidently the actual solubility curve between $15^{\circ}$ and $25^{\circ}$ is made up of two branches, each of which has slightly less curvature than is indicated by the total tendency, with a slightly greater curve in the middle. The deviations may be distributed among all the points, when Equation III results. This agrees with all the observed points within $4 \mathrm{mg}$. in each case.

$$
\log S=0.659970+0.02963889 t+0.0000688925 t^{2} .
$$

A better agreement is to be had by applying small corrections to the values given by Equation II, the corrections being computed graphically by plotting the deviations given in the fourth column of Table IV, depicted in the sinuous curve at the bottom of the diagram. The corrections thus found could hardly be less accurate than the readings of the thermometer, and are probably more accurate than the values given by Equation III. The following table (Table V) gives the results thus computed for the solubility of sodium sulfate.

\begin{tabular}{|c|c|c|}
\hline $\begin{array}{l}\text { Temperature, } \\
\text { Paris bydrogen scale. }\end{array}$ & $\begin{array}{c}\text { TABLE V. } \\
\text { Correction to be } \\
\text { added to Eq. } \\
\text { Calc. value. Eq. II. }\end{array}$ & $\begin{array}{l}\text { Corrected calc value. } \\
\text { Solubility of } \mathrm{Na}_{2} \mathrm{SO}_{110 \mathrm{H}} \mathrm{O} \text {. } \\
\text { G. Na2 } \mathrm{NO} \text {, in } 100 \mathrm{~g} . \mathrm{H}_{3} \mathrm{O} \text {. }\end{array}$ \\
\hline I $5.000^{\circ}$ & $\neq 0.000$ & 13.181 \\
\hline I $6.000^{\circ}$ & +0.003 & 14.185 \\
\hline $17.000^{\circ}$ & +0.005 & 15.268 \\
\hline $18.000^{\circ}$ & +0.005 & 16.437 \\
\hline $19.000^{\circ}$ & +0.002 & 17.698 \\
\hline $20.000^{\circ}$ & \pm 0.000 & 19.064 \\
\hline $21.000^{\circ}$ & +0.005 & 20.549 \\
\hline $22.000^{\circ}$ & to.009 & 22.155 \\
\hline $23.000^{\circ}$ & +0.008 & 23.888 \\
\hline $24.000^{\circ}$ & +0.003 & $25 \cdot 762$ \\
\hline $25.000^{\circ}$ & \pm 0.000 & 27.795 \\
\hline
\end{tabular}

These results are plotted in the accompanying graphs (diagrams). The values agree closely with Loewel's at $15^{\circ}$ and Lord Berkeley's at $24.90^{\circ}$, but show marked deviations from some of the other old data. ${ }^{1}$

1 Professor H. G. Deming has very kindly interpolated our experimental figures according to a different equation and one of his ingenious graphical methods. At only three of the eleven temperatures recorded above did his results differ over $3 \mathrm{mg}$. from the values given above, his method giving results decidedly closer to the experimental values than did the uncorrected Equation II. This outcome gives one confidence that the interpolation above recorded is very close to the truth. (See H. G. Deming, Thrs JoURNAL, 39, 2137 ( 1917$)$.) Lord Berkeley, in a kind letter just received, states that his records show his determination at $15.65^{\circ}$ to have been not very reliable. 


\section{The Comparison of the Baudin Thermometers with the Platinum Resistance Thermometer.}

The Baudin thermometers upon which the foregoing table rests were also compared with two platinum resistance thermometers, in the Jefferson Physical Laboratory of Harvard University, with the kind help of $\mathrm{H}$. N. Davis. The platinum thermometers were carefully standardized against ice, steam and the boiling point of sulfur. Great care was taken in this work, and it involved much time and labor. During the comparison the thermometers were immersed in a closed, cylindrical vessel, properly stirred, which in turn was placed wholly beneath the water of a thermostat. The details will be given in another place. The outcome was not very satisfactory: the five temperatures given in Table IV were found to be, respectively, $0.015,0.010,0.009$, 0.010 and $0.012^{\circ}$ higher as read by the platinum thermometer than as read by the Baudin thermometers. The platinum thermometers agreed with one another, but so also did the mercury thermometers, and the outcome points to an uncertainty of the thermometric scale in the neighborhood of $20^{\circ}$, amounting to about $0.01^{\circ}$. On applying these corrections a new series would, of course, be obtained to take the place of Table $\mathrm{V}$, the weight of dissolved salt being, roughly speaking, $0.07 \%$ less in each case, with some variation. We find ourselves unable to decide between these two thermometer scales. Those who prefer the platinum scale can easily compute from the data given the exact values of the corresponding figures. The uncertain part of the work is not the analytical determination, but rather the knowledge of the temperature. It is easy to measure the solubility as accurately as necessary.

Even as it is, the values given in Table V make possible the standardization of thermometers within $0.01^{\circ}$, which is about the limit of accuracy of reading the graph depicting the results. For this reason, in spite of the uncertainty, it seemed worth while to publish the results, especially because they are more complete than any which have yet been published on this subject, and because they exemplify a method which may, in the future, become really valuable and convenient, especially for the calibration of Beckmann thermometers. The present paper is to be looked upon merely as preliminary and subject to future revision when the normal state of the world has been restored.

We are indebted to the Carnegie Institution of Washington for some of the apparatus employed.

\section{Summary.}

The solubility of sodium sulfate may be conveniently used in determining temperatures between $15^{\circ}$ and $25^{\circ}$ because:

(a) The salt changes its solubility greatly with changing temperature;

(b) It is easily obtained pure;

(c) It attains the saturation point quickly from either direction; 
(d) The solubility is easily determined with accuracy.

Preliminary determinations of the solubility of the dekahydrate of sodium sulfate have been made at about $15^{\circ}, \mathrm{I} 7.5^{\circ}, 20^{\circ}$ and $25^{\circ}$, referred to the Paris hydrogen scale through standard Baudin thermometers.

Adequate constants for a usual empirical equation have been derived connecting temperature and solubility over this range, and the values at degree intervals have been computed.

The Baudin scale as given by these two thermometers does not exactly correspond with the platinum scale in this region. For the present we cannot explain the divergence, which diminishes the certainty of the results, but does not entirely destroy their usefulness.

CAMBridge, Mass.

\section{[CONTRIBUTION From the DEPARTMENT OF Chemistry OF CORNell University.]}

\section{EARTHS. III. ${ }^{1}$ \\ By L. M. Deignis and A. B. Ray. \\ Received November 12, 1917.}

THE ELECTROLYSIS OF SOLUTIONS OF THE RARE

\section{Electrolysis of Neutral Solutions of the Nitrates of the Rare Earths.}

In a previous article upon this subject, ${ }^{1}$ the fractional precipitation and separation of the rare earths by the electrolysis of aqueous solutions of their salts at voltages considerably higher than the decomposition values of these compounds were explained as probably due to the action of the hydroxyl ions, concentrated near the cathode, upon earths of different basicities, the hydroxide of the weakest base being precipitated first. If this explanation is correct, it follows that the selective precipitation of the hydroxides in the order of the basicities of the earths should proceed more evenly, and the separation of the earths be more complete, as the vigor with which the electrolyte is stirred is increased, because this would bring the hydroxyl ions more frequently into contact with the weakest bases and would thus tend to lessen the simultaneous precipitation of hydroxides of earths of different basicity.

With a view to gaining experimental evidence upon this point, two portions of a solution of certain rare earths were electrolyzed under identical conditions except that one solution was vigorously stirred, whereas the other was agitated just rapidly enough to keep the surface of the mercury cathode free from adherent deposit of the precipitated hydroxides. ${ }^{3}$

1. This article is a summary of a portion of the thesis presented to the Faculty of the Graduate School of Cornell University by A. B. Ray in partial fulfillment of the requirements for the degree of Doctor of Philosophy.

2 Dennis and van der Meulen, This JOURNAL, 37, 1963 (1915).

3 For detailed description of the apparatus that was used for the electrolysis see Dennis and van der Meulen, Loc. cit. 